\title{
Vitamin E in human serum and colostrum under fasting and postprandial conditions
}

\author{
Roberto Dimenstein, ${ }^{1}$ Ana C. P. Medeiros, ${ }^{2}$ Lahyana R. F. Cunha, ${ }^{3}$ \\ Katherine F. Araújo, ${ }^{4}$ Juliana C. O. Dantas, ${ }^{5}$ Thamizy M. S. Macedo, ${ }^{5}$ Tânia L. M. Stamford ${ }^{6}$
}

\begin{abstract}
Objective: To evaluate alpha-tocopherol concentrations in maternal serum and colostrum under fasting and postprandial conditions.

Methods: Thirty healthy childbearing women were recruited in a public maternity hospital, and samples of blood, fasting colostrum, and postprandial colostrum were collected from them up to 12 hours after delivery.

Results: The serum alpha-tocopherol concentration was $1,939.8 \pm 766.0 \mu \mathrm{g} / \mathrm{dL}$. Alpha-tocopherol levels in fasting colostrum $(1,603.4 \pm 911.0 \mu \mathrm{g} / \mathrm{dL})$ and in postprandial colostrum $(1,515.0 \pm 890.9 \mu \mathrm{g} / \mathrm{dL})$ did not demonstrate a statistically significant difference $(p>0.05)$. There was correlation between alpha-tocopherol levels in fasting and postprandial colostrum $(p<0.05)$, but not between serum and colostrum.

Conclusions: The lack of correlation between alpha-tocopherol levels in plasma and in colostrum, and the correlation between alpha-tocopherol concentrations in fasting and postprandial colostrum support the existence of a mechanism that controls the transfer of this nutrient, regardless of dietary intake.
\end{abstract}

J Pediatr (Rio J). 2010;86(4):345-348: Alpha-tocopherol, serum, colostrum.

\section{Introduction}

Vitamin $E$ is a generic term used to refer to eight natural compounds, among which alpha-tocopherol is the one with the highest biological activity. ${ }^{1}$ Epidemiological surveys have shown a probable implication of vitamin E deficiency in the pathogenesis of atherosclerosis, diabetes and some types of cancer, as well as in the modulation of inflammation and immune response. ${ }^{2}$

During pregnancy, the placental transfer of alphatocopherol is limited, and the fetus has a low circulating concentration of this vitamin. After delivery, breast milk is extremely important as a source of alpha-tocopherol for the newborn infant, as it is essential against oxygen toxicity and helps stimulate the development of the immune system. ${ }^{1}$

Newborn infants, especially preterm ones, can be prone to developing clinical symptoms such as hemolytic anemia, intraventricular hemorrhage and bronchopulmonary dysplasia as a result of alpha-tocopherol deficiency. ${ }^{3} \mathrm{~A}$ good supply of this vitamin to newborn infants is critical,

1. Doutor, Bioquímica. Professor adjunto IV, Departamento de Bioquímica, Centro de Biociências, Universidade Federal do Rio Grande do Norte (UFRN), Natal, RN, Brazil.

2. Farmacêutica. Mestranda, Curso de Pós-Graduação, Bioquímica, Centro de Biociências, Departamento de Bioquímica, UFRN, Natal, RN, Brazil.

3. Bióloga, mestranda, Curso de Pós-Graduação, Bioquímica, Centro de Biociências, Departamento de Bioquímica, UFRN, Natal, RN, Brazil.

4. Nutricionista, Bolsista de apoio técnico, Laboratório de Bioquímica da Nutrição, UFRN, Natal, RN, Brazil.

5. Acadêmica, Nutrição, UFRN, Natal, RN, Brazil.

6. Doutora, Nutrição. Professora associada, Departamento de Nutrição, Centro de Ciências da Saúde, Universidade Federal de Pernambuco (UFPE), Recife, PE, Brazil.

This study was conducted at the Departamento de Bioquímica, Centro de Biociências, Universidade Federal do Rio Grande do Norte (UFRN), Natal, RN, Brazil. Financial support: National Council for Scientific and Technological Development (Conselho Nacional de Desenvolvimento Científico e Tecnológico, CNPq), senior postdoctoral fellow. Process no. 151899/2008-8.

No conflicts of interest declared concerning the publication of this article.

Suggested citation: Dimenstein R, Medeiros AC, Cunha LR, Araújo KF, Dantas JC, Macedo TM, et al. Vitamin E in human serum and colostrum under fasting and postprandial conditions. J Pediatr (Rio J). 2010;86(4):345-348.

Manuscript submitted Jul 23 2009, accepted for publication Dec 112009.

doi:10.2223/JPED.1971 
chiefly among those from low-income families or for whom breastfeeding is not guaranteed. ${ }^{4}$

Colostrum contains a high concentration of alphatocopherol, reaching levels that are six to seven times greater than those of mature milk ${ }^{5}$; however, the transfer of alpha-tocopherol to the mammary gland is not fully understood.

There is evidence that the daily secretion of alphatocopherol is limited in terms of quantity and does not rely on the volume and contents of fat of the produced milk. ${ }^{6}$ Therefore, given the importance of vitamin $E$ to the development of infants, our aim was to investigate the relationship between alpha-tocopherol in human serum and in colostrum, and to assess the influence of fasting and postprandial periods on the concentration of vitamin $E$ in the colostrum.

\section{Methods}

This was a cross-sectional study that used a convenience sample consisting of volunteer childbearing women, followed up at Januário Cicco maternity teaching hospital, Natal, Brazil. The sample size was calculated using Statcalc (Epi-Info, version 3.5.1), considering an average of 250 deliveries/month, and a minimum sample of 30 subjects as representative of the maternity ward for a $95 \%$ confidence interval $(95 \% \mathrm{CI})$. The study protocol was approved by the |Research Ethics Committee of Universidade Federal do Rio Grande do Norte (UFRN), Natal, Brazil (Protocol no. 284/09).

Only women who were free of any diseases, such as diabetes, neoplasias, gastrointestinal and liver disorders, cardiopathies, infectious diseases, syphilis and human immunodeficiency virus (HIV) and who gave birth to fullterm singletons without any malformation were included in the study. The participating mothers reported no use of vitamin $\mathrm{E}$ supplements during pregnancy.

The first blood samples were collected after a fasting period, always in the morning, followed by collection of 2 $\mathrm{mL}$ of colostrum, also after a fasting period. Colostrum was collected again $3 \mathrm{~h}$ after breakfast. Therefore, colostrum was collected from each patient twice a day. These collections were performed up to 12 hours after delivery. Colostrum was obtained by manual expression of a single breast at the beginning and at the end of the breastfeed in order to avoid variation in fat contents.

A 3-mL fasting blood sample was collected and stored in a polypropylene tube protected from the sunlight. Milk and blood samples were transported under refrigeration to the research laboratory of Nutritional Biochemistry, Department of Biochemistry, Biosciences Center, UFRN, Natal, Brazil. The blood aliquots were centrifuged for 10 minutes $(500 \mathrm{xg}$ ) for separation and removal of serum. Milk and serum were stored at $-20{ }^{\circ} \mathrm{C}$ until analysis.
The milk and serum samples were extracted according to a modified version of the technique developed by Ortega et al. ${ }^{7}$ Aliquots of 2 and $3 \mathrm{~mL}$ from the hexane phase were used for colostrum and serum, respectively. The extracts were dissolved again in $500 \mu \mathrm{L}$ of ethanol (Merck, São Paulo, Brazil), in degree of purity for high-performance liquid chromatography, and $20 \mu \mathrm{L}$ was applied to a Shimadzu chromatograph, with an LC-20 AT Shimadzu pump, coupled to an SPD-20A Shimadzu UV-VIS detector and Shim-Pack CLC-ODS (M) column $(4.6 \mathrm{~mm} \times 15 \mathrm{~cm})$. The data were processed using the LC Solution software (Shimadzu Corporation). The mobile phase used for colostrum was methanol:water (97:3), in an isocratic system with a flow of $1.5 \mathrm{~mL} /$ minute and a wavelength of $292 \mathrm{~nm}$. The mobile phase for serum was methanol $100 \%$.

The identification and quantification of alpha-tocopherol in the samples were established by comparison of the respective area of the peak obtained in the chromatogram with the standard area of alpha-tocopherol (SIGMA, St. Louis, USA). The concentration of the standard was confirmed by the alpha-tocopherol-specific extinction coefficient (E 1\%, $1 \mathrm{~cm}=75.8$, at $292 \mathrm{~nm}$ ) in absolute ethanol (Vetec) ${ }^{8}$

The serum concentration of alpha-tocopherol was expressed in $\mu \mathrm{g} / \mathrm{dL}$. Serum alpha-tocopherol levels: < 499.6 (insufficient level), 499.6 to 697.7 (low level) and $>697.7$ (acceptable level). ${ }^{9}$

\section{Statistical analysis}

Alpha-tocopherol levels were expressed as mean and standard deviation. The Student's $t$ test for paired samples was used to check the differences between the means of parametric numerical data. The differences were significant when $p<0.05$. The association between continuous variables (concentration of nutrients in milk and serum) was determined by Pearson's correlation.

\section{Results}

The samples were collected from 30 women and were classified as follows: serum, fasting colostrum and postprandial colostrum.

The mean concentration of alpha-tocopherol found in serum was $1,939.8 \pm 766.0 \mu \mathrm{g} / \mathrm{dL}$, which is considered to be adequate according to reference values. The concentration of alpha-tocopherol in fasting colostrum $(1,603.4 \pm 911.0 \mu \mathrm{g} / \mathrm{dL})$ and postprandial colostrum $(1,515.0 \pm 890.9 \mu \mathrm{g} / \mathrm{dL})$ did not show any statistically significant difference $(p=0.55)$.

No correlation was observed between alpha-tocopherol concentrations in serum and in colostrum, neither under fasting nor under postprandial conditions. However, there was a strong correlation between alpha-tocopherol concentrations in fasting colostrum and in postprandial colostrum ( $p=0.001, r=0.596)$. This finding was 
corroborated when we simulated the correlation in the group of childbearing women by categorizing them according to the concentration of serum alpha-tocopherol. Fourteen women had a serum alpha-tocopherol concentration lower than $2,000 \mu \mathrm{g} / \mathrm{dL}$, and 16 women had levels greater than $2,000 \mu \mathrm{g} / \mathrm{dL}$ (Table 1 ). The correlation between alphatocopherol levels in fasting colostrum and in postprandial colostrum was stronger ( $p=0.017, r=0.621$ ) in the group with lower serum alpha-tocopherol concentrations than in the group with higher concentrations $(p=0.029$, $r=0.544)$.

\section{Discussion}

The mean age of participants was 24 years and $66.6 \%$ of them had one or two children. C-sections were performed in $46.3 \%$ of the participants whereas vaginal delivery accounted for $53.6 \%$.

Serum alpha-tocopherol levels indicate good vitamin E nutritional status, which means that an appropriate diet was followed during pregnancy. When alpha-tocopherol levels were compared with those obtained in other studies, their means $(1,938.1 \pm 766.6 \mu \mathrm{g} / \mathrm{dL})$ were higher than those found in U.S. women $(1,128.4 \mu \mathrm{g} / \mathrm{dL})^{10}$ and in Cuba $(1,029.4 \mu \mathrm{g} / \mathrm{dL}) .{ }^{11}$ An explanation for the higher levels of serum alpha-tocopherol observed in our study can be related to the fact that the U.S. diet contains a higher amount of gamma-tocopherol than of alpha-tocopherol. ${ }^{12}$

The concentration of alpha-tocopherol in the fasting colostrum group $(1,603.4 \pm 911.0 \mu \mathrm{g} / \mathrm{dL})$ was similar to that found in $\mathrm{Cuba}^{13}$ and lower than that of Germany. ${ }^{14}$

Alpha-tocopherol levels in postprandial colostrum were not significantly different from those of fasting colostrum, that is, alpha-tocopherol levels did not rise after breakfast, indicating that the transfer of this vitamin is restricted, ${ }^{7}$ or that the amount found in the diet was not enough to increase its levels.

The lack of correlation between serum alpha-tocopherol and that found in fasting or postprandial colostrum rules out the existence of passive mechanisms during the transfer of vitamin E from the mammary gland to breast milk. Probably, there must be different mechanisms for the transfer of this vitamin to the mammary gland that do not depend upon plasma concentrations. ${ }^{15}$ Actually, the reduction of alpha-tocopherol levels in colostrum by nearly 10 times compared to the levels found in transitional and mature milk points to other transfer mechanisms. ${ }^{1}$

The significant correlation between alpha-tocopherol levels in fasting and postprandial colostrum demonstrates that this vitamin will not be restricted in different moments of the maternal diet after the mammary gland transfer barrier is overcome and milk secretion eventually takes place. The strongest correlation found in the group with the lowest serum alpha-tocopherol levels is compatible with the findings of Jensen et al., ${ }^{6}$ who showed that the secretion of alpha-tocopherol from blood into milk, in cows, follows the Michaelis-Menten kinetics for active transport across membranes. Therefore, in the presence of lower serum concentrations of alpha-tocopherol, lipoprotein receptors are not totally saturated, and all of the alpha-tocopherol that reaches the receptors is transferred to milk.

The evidence found under postprandial conditions indicates limited transfer of alpha-tocopherol from maternal serum to colostrum, raising the question about whether mothers should receive vitamin $\mathrm{E}$ supplementation at this postpartum stage in order to improve the infant's nutritional status.

\section{Acknowledgements}

We express our thanks to Januário Cicco maternity teaching hospital for allowing the collection of biological samples.

The data presented in this article are part of the postdoctoral research project carried out by the first author.

Financial support: CNPq, senior postdoctoral fellow - Process no. $151899 / 2008-8$.

Table 1 - Correlation between alpha-tocopherol in fasting and postprandial colostrum in groups with lower $(<2,000 \mu \mathrm{g} / \mathrm{dL})$ and higher $(>2,000 \mu \mathrm{g} / \mathrm{dL})$ mean serum concentration of alpha-tocopherol

\begin{tabular}{|c|c|c|c|}
\hline Alpha-tocopherol $(\mu \mathrm{g} / \mathrm{dL})$ & Serum & $\mathbf{p}$ & $\mathbf{r}$ \\
\hline \multicolumn{4}{|l|}{ Group $<2,000 \mu \mathrm{g} / \mathrm{dL}(\mathrm{n}=14)$} \\
\hline Fasting vs. postprandial colostrum & $1,283.9 \pm 448.0$ & 0.017 & 0.621 \\
\hline \multicolumn{4}{|l|}{ Group $>2,000 \mu \mathrm{g} / \mathrm{dL}(\mathrm{n}=16)$} \\
\hline fasting vs. postprandial colostrum & $2,513.7 \pm 455.8^{*}$ & 0.029 & 0.544 \\
\hline
\end{tabular}

* Statistically significant difference - Student's $t$ test for independent samples $(p<0.0001)$. 


\section{References}

1. Debier C, Larondelle Y. Vitamins A and E: metabolism, roles and transfer to offspring. Br J Nutr. 2005;93:153-74

2. Azzi A, Ricciarelli R, Zingg JM. Non-antioxidant molecular functions of alpha-tocopherol (vitamin E). FEBS Lett. 2002;519:8-10.

3. Romeu-Nadal M, Morera-Pons S, Castellote AI, López-Sabater MC. Determination of gamma- and alpha-tocopherols in human milk by a direct high-performance liquid chromatographic method with UV-vis detection and comparison with evaporative light scattering detection. J Chromatogr A. 2006;1114:132-7.

4. Debier C, Pomeroy PP, Baret PV, Mignolet E, Larondelle Y. Vitamin $E$ status and the dynamics of its transfer between mother and pup during lactation in grey seals (Halichoerus grypus). Can J Zool. 2002;80:727-37.

5. Kelly FJ, Rodgers W, Handel J, Smith S, Hall MA. Time course of vitamin $\mathrm{E}$ repletion in the premature infant. $\mathrm{Br} \mathrm{J}$ Nutr. $1990 ; 63: 631-8$.

6. Jensen SK, Johannsen AK, Hermansen JE. Quantitative secretion and maximal secretion capacity of retinol, beta-carotene and alpha-tocopherol into cows' milk. J Dairy Res. 1999;66:511-22.

7. Ortega RM, López-Sobaler AM, Martínez RM, Andrés P, Quintas ME. Influence of smoking on vitamin E status during the third trimester of pregnancy and on breast-milk tocopherol concentrations in Spanish women. Am J Clin Nutr. 1998;68:662-7.

8. Nierenberg DW, Nann SL. A method for determining concentrations of retinol, tocopherol, and five carotenoids in human plasma and tissue samples. Am J Clin Nutr. 1992;56:417-26.

9. Morrissey PA, Sheehy PJ. Optimal nutrition: vitamin E. Proc Nutr Soc. $1999 ; 58: 459-68$.

10. Ascherio A, Stampfer M, Colditz GA, Rimm EB, Litin L, Willett WC. Correlations of vitamin $A$ in $E$ intakes with the plasma concentrations of carotenoids and tocopherols among American men and women. J Nutr. 1992;122:1792-801.
11. Rodriguéz GP, Alonso DP, Sintes GS, Matos CM, Hernandez AC, Enríques $Y R$, et al. Vitaminas antioxidantes en un grupo de embarazadas y recién nacidos durante un año de estudio. Rev Cubana Aliment Nutr. 2002;16:85-94.

12. Traber MG. Vitamin E. In Present Knowledge in Nutrition. 9th edition. Edited by: Bowman BA, Russell RM. Washington, D.C.: ILSI Press; 2007. p. 211-19.

13. Macias C, Schweigert FJ. Changes in the concentration of carotenoids, vitamin A, alpha-tocopherol and total lipids in human milk throughout early lactation. Ann Nutr Metab. 2001;45:82-5.

14. Schweigert FJ, Bathe K, Chen F, Büscher U, Dudenhausen JW. Effect of the stage of lactation in humans on carotenoid levels in milk, blood plasma and plasma lipoprotein fractions. Eur J Nutr. 2004;43:39-44.

15. de Azeredo VB, Trugo NM. Retinol, carotenoids, and tocopherols in the milk of lactating adolescents and relationships with plasma concentrations. Nutrition. 2008;24:133-9.

Correspondence:

Roberto Dimenstein

Departamento de Bioquímica, Centro de Biociências, Universidade Federal do Rio Grande do Norte

Av. Senador Salgado Filho, 3000

CEP 59072-970 - Natal, RN - Brazil

Tel.: +55 (84) 3215.3416, ext. 205

Fax: +55 (84) 3211.9208

E-mail: robertod@ufrnet.br 